\title{
A case of polyuria
}

Joaquim Calado

Department of Nephrology, Centro Hospitalar de Lisboa Central; Lisboa, Portugal

\section{CLINICAL VIGNETTE}

We present the case of a 39-year-old woman referred to the nephrology outpatient unit with polyuria (daily urinary output of 12 L). At the age of 36, she was diagnosed with primary Sjögren's syndrome (pSS), according to the 2017 ACR-EULAR criteria ${ }^{1}$. She was medicated with hydroxychloroquine. The Sicca syndrome was quite exuberant and she persistently drank increasing amounts of water. Two years later, at the age of 38 , a kidney biopsy was performed in light of the findings of persistently elevated serum creatinine of 1.5 $\mathrm{mg} / \mathrm{dl}$, which revealed a chronic tubulointerstitial nephritis (TIN) displaying interstitial infiltration with lymphocytes and plasmocytes (Figure 1). Immune deposits were distinctly absent. Prednisone was initiated at a daily dose of $20 \mathrm{mg}$.

\section{Figure 1}

Kidney biopsy. Hematoxylin \& Eosin X200, displaying interstitial mononuclear infiltration.

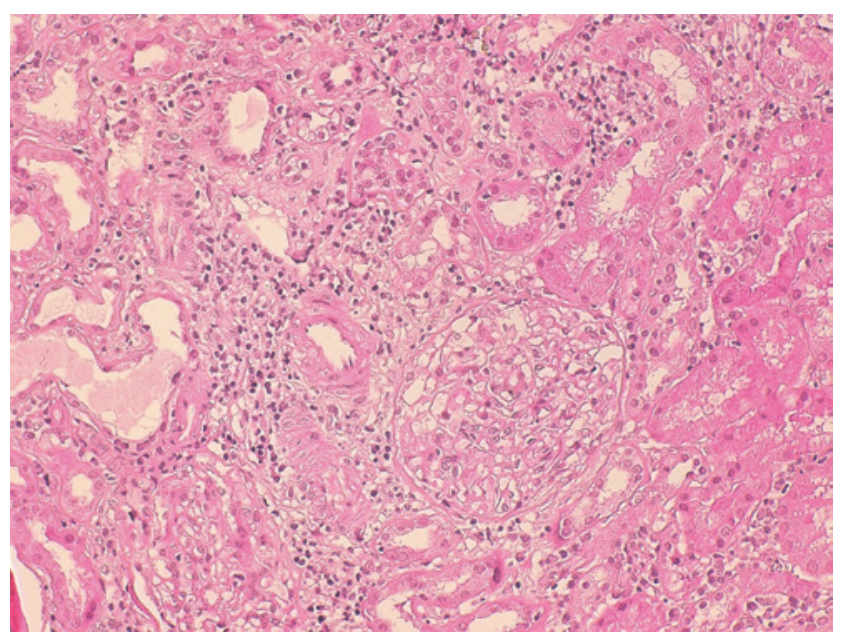

\section{WHAT IS THE CAUSE OF POLYURIA IN THIS PATIENT?}

In order to determine the cause of the polyuria, as defined by a urine output in excess of $50 \mathrm{ml} / \mathrm{kg} /$ day, one must first exclude osmotic diuresis. Since the patient displayed low urine osmolality in our initial assessment (Table 1), this could be ruled out. Although a central diabetes insipidus cannot be excluded a priori, in light of the clinical vignette presented, two different diagnoses are to be prioritized: primary polydipsia vs. acquired nephrogenic diabetes insipidus (NDI). The former, induced or perpetuated by the Sicca syndrome, and the latter as a direct consequence of pSS renal involvement. Nevertheless, the fact that the patient was presenting with hypernatremia (Table 1) and not hypotonic polyuria, is a strong argument in favor of diabetes insipidus. To address the differential diagnosis, a modified water deprivation test ${ }^{2}$ was performed with subsequent administration of 1-desamino-8-D-arginine vasopressin (DDAVP) (Figure 2 and Table 2).

Briefly, water ingestion was restricted for the entire duration of the test. Two mcg of DDAVP were administered once $3 \%$ of the initial weight was lost or a sodium ( $\mathrm{Na}$ ) serum concentration $>145 \mathrm{mmol} / \mathrm{L}$ had been reached. Blood and urine samples were periodically collected for osmolality assessment. Since we were not able to measure serum or urine osmolality, these were inferred using validated formulas:

$$
2 \times N a+\frac{B U N}{2,8}+\frac{\text { Glucose }}{18} \text { for serum, and } 2 \times N a+K+\frac{B U N}{2,8}+\frac{\text { Glucose }}{18}
$$

for serum, and for urine, with urea $(\mathrm{mg} / \mathrm{dl})$ divided by 2.14 in order to obtain BUN (blood urea nitrogen in $\mathrm{mg} / \mathrm{dl}$ ). The fact that we had to rely on the estimation rather than the actual measurement of osmolality is a major limitation of this case presentation.

At test initiation, the patient presented with a serum osmolality of $294 \mathrm{mOsm} / \mathrm{Kg}$ ( $\mathrm{Na}$ of $142 \mathrm{mmol} / \mathrm{L}$ ). Surreptitious water ingestion during the test could be excluded, since the patient lost weight throughout the test (-1.46\%). Despite water deprivation, the accompanying weight lost and increase in serum osmolality, there was no increase in urine osmolality before DDAVP, with values remaining

\section{$\underline{\text { Table } 1}$}

Laboratory values at presentation.

\begin{tabular}{l|c|c}
\multicolumn{2}{|c|}{ Blood chemistry } & Reference \\
\hline BUN (urea) & $26(57)$ & $7-17(15-40) \mathrm{mg} / \mathrm{dl}$ \\
$\mathrm{Na}$ & 147 & $136-145 \mathrm{mmol} / \mathrm{L}$ \\
\hline Glucose & 79 & $60-100 \mathrm{mg} / \mathrm{dl}$ \\
osmolality* & 308 & $283-293 \mathrm{mOsm} / \mathrm{Kg}$ \\
\hline Urine chemistry & & $\mathrm{ml} / \mathrm{d}$ \\
\hline volume & 12000 & $\mathrm{mmol} / \mathrm{L}$ \\
\hline $\mathrm{Na}$ & 24 & $\mathrm{mmol} / \mathrm{L}$ \\
\hline $\mathrm{K}$ & 5 & $\mathrm{mg} / \mathrm{dl}$ \\
\hline glucose & 0 & $50-1200 \mathrm{mOsm} / \mathrm{Kg}$ \\
osmolality* & 75 & \\
\hline
\end{tabular}

BUN: blood urea nitrogen; ${ }^{*}$ calculated 


\section{Table 2}

Water deprivation test interpretation $(\mathrm{m0sm} / \mathrm{Kg})$

\begin{tabular}{c|c|c|c}
\multicolumn{2}{c|}{ Post-dehydration } & Post DDAVP & \multirow{2}{*}{ Diagnosis } \\
\cline { 1 - 2 } Serum & Urine & Urine & \\
\hline $283-293$ & $>750$ & $>750$ & normal \\
$>293$ & $<300$ & $<300$ & NDI \\
$>293$ & $<300$ & $>750$ & central DI \\
$<293$ & $300-750$ & $<750$ & chronic polydipsia
\end{tabular}

below $300 \mathrm{mOsm} / \mathrm{Kg}$. These findings rule out primary polydipsia. DDAVP was administered after $6 \mathrm{~h}: 15 \mathrm{~min}$, but the patient continued to lose weight and failed to significantly increase urine osmolality, once again remaining below $300 \mathrm{mOsm} / \mathrm{Kg}$ and establishing renal insensitivity to DDAVP as the cause of polyuria (Figure 2 and Table 2).

Recently, the possibility of determining plasma concentration of copeptin, a 39-amino acid C-terminal glycoprotein moiety of pre-pro vasopressin, which is a surrogate (and more stable) marker of vasopressin secretion, has led to the development of stimulated copeptin measurements as an alternative to the water deprivation test for the evaluation of polyuric states ${ }^{3,4}$.

Sjögren's syndrome is a rare cause of NDI. Lithium treatment underlies most of acquired NDI cases in the adult population, affecting up to $85 \%$ of treated individuals ${ }^{5}$. Other causes of NDI are displayed in Table $3^{6}$. In particular, the inherited (congenital) forms are either due

\section{Table 3}

Most frequent causes of NDI

\begin{tabular}{|l|l} 
Congenital & $\begin{array}{l}\text { X-linked (AVPR2) } \\
\text { Autosomal recessive (AQP2) }\end{array}$ \\
$\begin{array}{l}\text { Acquired } \\
\text { Drugs }\end{array}$ & Lithium \\
& Amphotericin B \\
Demeclocycline \\
Electrolyte & Hypercalcemia \\
& Hypokalemia \\
Systemic & Sjögren's syndrome \\
& Sickle cell disease \\
& Sarcoidosis \\
\hline
\end{tabular}

to pathogenic variants in the AVPR2 gene ( $\mathrm{X}$ linked pedigrees), coding for vasopressin $\mathrm{V} 2$ receptor or, less frequently, in the $A Q P 2$ gene (autosomal recessive forms) that codes for aquaporin 2 .

\section{HOW TO MANAGE (ACQUIRED) NDI?}

Management of acquired NDI is focused on the treatment of the underlying condition.

Regardless of the cause, however, similar pathophysiological considerations are warranted, and these have therapeutic implications:

\section{Figure 2}

Water deprivation test. See text for details. S. osmol, serum osmolality; U. osmol, urine osmolality; DDAVP, 1-desamino-8-D-arginine vasopressin.

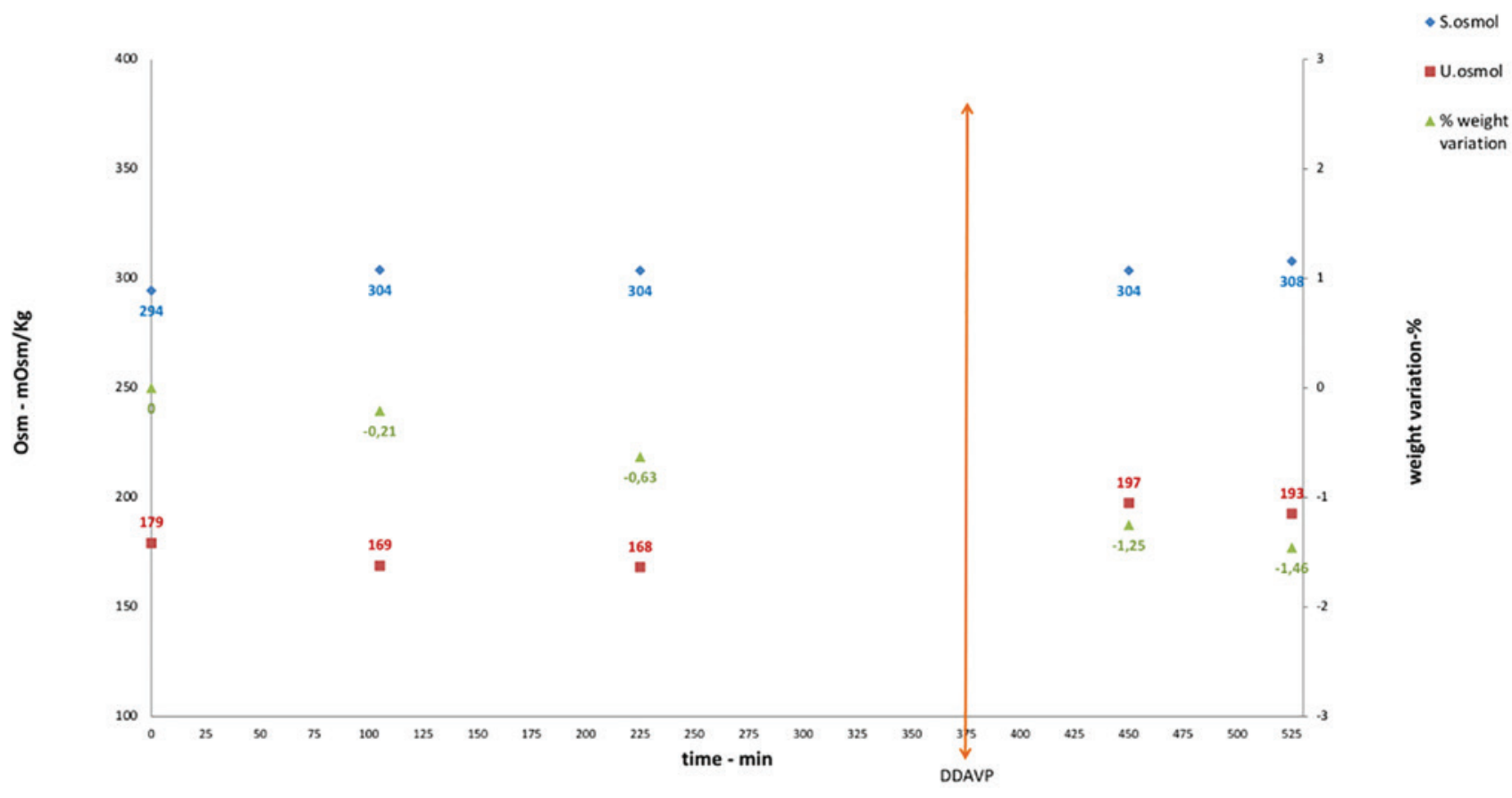


Preventing hypernatremic dehydration. Easy access to unlimited amounts of water must be provided. This is critical in hospitalized patients, namely if bedridden. Psychiatric cases, with severe NDI due to lithium intoxication, in whom there may be a need for sedation, are particularly challenging. Hypotonic solution must therefore be provided either enterically (water) or intravenously ( $5 \%$ dextrose in water $)^{5}$.

Diet. Reducing osmolar load, in order to minimize water losses, is mandatory. Proteins and salts are the major contributors to osmol loads. For instances, if a patient has a urine osmolality of $100 \mathrm{mOsm} /$ $\mathrm{Kg}$, each gram of ingested salt will carry an obligate loss of $360 \mathrm{ml}$ of urine ${ }^{5}$. Therefore, in the pediatric setting, minimizing osmolar load while preserving caloric and protein intake to maintain normal growth is crucial.

Thiazides diuretics. Na reabsorption in the distal tubule is essential for urine dilution. Therefore, inhibition of the thiazide-sensitive co-transporter SLC12A3 in the diluting segment of the nephron will minimize urinary free water losses. In addition, volume depletion mediated by the increased urinary $\mathrm{Na}$ excretion will enhance proximal isotonic reabsorption with less water being presented to the collecting duct. Finally, and in the particular case of lithium-induced NDI, the association of a thiazide with amiloride might be particular useful, since the latter has been shown to block lithium luminal entry to principal cells by closing the $\mathrm{ENaC}^{6}$.

Prostaglandins synthesis inhibitors. Indomethacin was initially shown to have a synergistic effect with arginine vasopressin, but a similar effect was also observed in NDI. Those observations, in both central DI as well as NDI, are a consequence of the enhanced proximal reabsorption of salt and water by indomethacin. In the patient presented here, and in light of the documented TIN, the use of indomethacin, however, may further deteriorate renal function.

\section{Acknowledgments}

The author is grateful to Dr Mário Gois for providing the microphotographs of patient's kidney biopsy.

Disclosure of potential conflicts of interest: none declared

\section{References}

1. Shiboski CH, Shiboski SC, Seror R, et al. 2016 American College of Rheumatology/European League Against Rheumatism classification criteria for primary Sjögren's syndrome: a consensus and data driven methodology involving three international patient cohorts. Ann Rheum Dis 2017;76:9-16. 2. Utiger RD. Disorders of antidiuretic hormone secretion. Med Clin North Am 1968:52:381-391.

3. Fenske W, Refardt J, Chifu I, et al. A copeptin-based approach in the diagnosis of diabetes insipidus. N Engl J Med 2018;379:428-439.

4. Winzeler B, Cesana-Nigro N, Refardt J, et al. Arginine-stimulated copeptin measurements in the differential diagnosis of diabetes insipidus: a prospective diagnostic study. Lancet 2019;394:587-595 .

5. Bockenhauer D, Bichet DG. Pathophysiology, diagnosis and management of nephrogenic diabetes insipidus. Nat Rev Nephrol 2015;11:576-588. PMID: 26077742

6. Khanna A. Acquired nephrogenic diabetes insipidus. Semin Nephrol 2006;26:244-248.

\section{Correspondence to:}

Joaquim Calado, MD, PhD

Department of Nephrology, Centro Hospitalar de Lisboa Central

E-mail: jcalado@nms.unl.pt 